Mariana Watanabe Barbosa

Mestra, Universidade Anhembi Morumbi São Paulo/ marianawatanabe.b@gmail.com Orcid: 0000-0002-8424-2466/ lattes

Cristiane Ferreira Mesquita

Doutora, Universidade Anhembi Moumbi São Paulo/ cfmesquita@anhembi.br

Orcid: 0000-0001-6860-0676/ lattes 


\title{
Wabi-sabi e cultivo de si no processo de criação da coleção de design de moda Comunidade Yuba
}

\begin{abstract}
RESUMO
Este artigo aborda a presença da estética tradicional japonesa wabi-sabi na coleção Comunidade Yuba, da designer de moda nipo-brasileira Fernanda Yamamoto. A experiência junto a esta comunidade agrícola formada por nipo-brasileiros, localizada na cidade de Mirandópolis, interior paulista, sustentada pelo tripé "cultivar a terra, amar as artes e orar" e referencia os processos de criação e produção das peças do desfile e das fotos que apresentam o trabalho. A estética wabi-sabi relaciona-se com a beleza que eclode da simplicidade e do decorrer do tempo, variáveis que são identificadas nos processos do trabalho em questão.
\end{abstract}

Palavras-chave: Design de moda. Fernanda Yamamoto. Comunidade Yuba. 


\title{
Wabi-sabi and Self-cultivation in the process of creating the Yuba Community fashion design collection
}

\begin{abstract}
This article aims to discuss the presence of traditional Japanese wabi-sabi aesthetic in the Yuba Community collection, by the Japanese-Brazilian fashion designer Fernanda Yamamoto. The experience with this agricultural community formed by Japanese-Brazilians, located in the city of Mirandópolis, São Paulo, supported by the tripod "cultivate the land, love the arts and pray" and refers to the processes of creation and production of the pieces of the parade and the photos which encompass the core of the presentation of this work. The wabi-sabi aesthetic relates to the beauty that erupts from simplicity and the course of time, variables that are identified in the processes of the work in question.
\end{abstract}

Keywords: Fashion design. Fernanda Yamamoto. Yuba Community. 


\title{
Wabi-sabi y autocultivo en el proceso de creación de la colección de diseño de moda Yuba Community
}

\begin{abstract}
O
Este artículo aborda la presencia de la estética tradicional japonesa wabi-sabi en la colección Comunidade Yuba, de la diseñadora de moda japonés-brasileña Fernanda Yamamoto. La experiencia con esta comunidad agrícola formada por japoneses-brasileños, ubicada en la ciudad de Mirandópolis, en el interior de São Paulo, apoyada en el trípode "cultivar la tierra, amar las artes y rezar" y referenciar los procesos de creación y producción de las piezas del desfile y las fotos que presentan la obra. La estética wabi-sabi está relacionada con la belleza que surge de la sencillez y el paso del tiempo, variables que se identifican en los procesos de trabajo en cuestión.
\end{abstract}

Palabras clave: Diseño de moda. Fernanda Yamamoto. Comunidad Yuba. 


\section{INTRODUÇÃO}

'Este artigo é parte da dissertação de mestrado "Singularidades mestiças: percursos e criação no design da coleção Comunidade Yuba", que investiga a estética japonesa wabi-sabi como um rastro ancestral ${ }^{1}$, presente na coleção e no desfile Comunidade Yuba, realizados pela designer de moda nipo-brasileira Fernanda Yamamoto, na edição 45 da São Paulo Fashion Week $^{2}$. Desenvolveremos uma relação entre o processo de criação da coleção Comunidade Yuba e essa estética tradicional japonesa por considerá-la predominante neste trabalho.

Aqui, o design de moda é visto a partir de uma perspectiva ampliada considerando a relação entre sujeitos e roupas como forças relevantes dos processos de subjetivação, compondo o território existencial de um sujeito no mundo em suas relações com a aparência. Assim, este trabalho se situa na intersecção entre design de moda e psicologia, transversalizando saberes deste que versam sobre ancestralidades, cuidado de si e práticas de clínica ampliada. ${ }^{3}$

A metodologia de pesquisa que nos orientou foi a cartografia, baseada nos escritos do filósofo Gilles Deleuze e do psicanalista Félix Guattari (2000), que propõem acompanhar fenômenos psicossociais, levando em conta que estes também podem ser cartografados por serem entendidos como "territórios". Acompanham-se processos a partir de suas conexões relacionais e da vitalidade envolvida no ato de pesquisar. A psicanalista Suely Rolnik (1989) aponta que o 
pesquisador-cartógrafo tem como principal ferramenta a sua sensibilidade de escuta dos movimentos vitais que acontecem no campo a ser pesquisado. Para tanto, o pesquisador utilizase de diferentes ferramentas teóricas e práticas, desde que elas deem expressão e criem sentido para o que o próprio processo de pesquisa for trazendo à tona. Em suma, "todas as entradas são boas desde que as saídas sejam múltiplas" (ROLNIK, 1989, p.66).

Tomando esta ética enquanto um guia, nos munimos em nosso trabalho de ferramentas teóricas advindas da psicologia, da filosofia, dos estudos estéticos japoneses, da sociologia e da história. Além disso, realizamos uma visita de campo à Comunidade Yuba, na qual pudemos vivenciar o cotidiano comunitário, baseado no tripé de "cultivar a terra, amar as artes e orar".

Durante os nossos dias na comunidade, conversamos com os seus membros e vivenciamos as suas atividades cotidianas, de modo que pudemos estar mais próximos à estética wabisabi, enquanto algo presente no modo de vida yubense.

Por fim, para a nossa pesquisa documental, realizamos uma entrevista com a equipe de criação da designer Fernanda Yamamoto e também uma investigação dos materiais advindos do processo de criação aqui estudado, como cartela de cores, croquis, fotografias, dentre outros. Para tanto, guiamo-nos pela metodologia de acompanhamento de processos de criação denominada "crítica de processos", proposta pela crítica de arte Cecília de Almeida Salles (2016). Ela atenta para os documentos e outros vestígios que compõem o trajeto de um processo de criação em arte - a rede relacional da criação que ocorre de forma conectiva e não linear. Os componentes desta rede são dinâmicos, não hierárquicos e incluem uma simultaneidade de ações, da qual fazem parte as relações entre os criadores e as tradições, 
tendo em vista que a memória cultural não é estática e que um processo de criação, que se relaciona com tradições, as reconstrói incessantemente.

O trajeto deste artigo inicia-se com a contextualização dos processos de criação da designer Fernanda Yamamoto. Posteriormente focaremos no processo de criação da coleção Comunidade Yuba. Adentraremos a estética wabi-sabi e, por fim, teceremos articulações com a coleção elaborada pela designer.

\section{OS PROCESSOS DE CRIAÇÃO DE FERNANDA YAMAMOTO}

Fernanda Yamamoto é uma designer de moda que vive e trabalha em São Paulo, graduada em administração de empresas pela Fundação Getúlio Vargas de São Paulo, 2000. Em 2006 consolida uma mudança de área ao se formar em moda pela Parsons The New School of Fashion (Nova Iorque). Em 2007, cria uma marca autoral e em 2009 inaugura sua loja ateliê no bairro da Vila Madalena. A partir de 2010, começa a desfilar na São Paulo Fashion Week. E apresentou as suas criações em eventos internacionais, como a Tokyo Fashion Week (2010), no Japão, e o Raiz Diseño (2017), no Chile. Em 2014, a designer recebe o primeiro lugar no Prêmio Design do Museu da Casa Brasileira, pelo trabalho chamado Quadrados.

Para contextualização, vale enfatizar que Yamamoto entende que 0 processo criativo envolvido no desenvolvimento de uma coleção pode funcionar como uma forma de autoconhecimento, pois toca em uma série de questões que concernem à pessoalidade daquele que cria, refletindo momentos de vida e desejos. Este enfoque pessoal presente na criação autoral não desmerece os processos 
criativos que ocorrem de forma coletiva, agregando todas as pessoas de sua equipe, (YAMAMOTO, 2015, informação oral).

Em meados de 2015, limita suas participações na SPFW a apenas um desfile anual, por entender a sua construção de coleções como a parte de processos profundos e que exigem períodos de tempo mais longos, depois dos quais os desfiles tornam-se um ápice criativo que sintetiza e transmite os principais conceitos. Sua marca procura e traz como pilares o trabalho de pesquisa de materiais, priorizando a sustentabilidade como um valor importante, a construção de modelagens preocupadas com funcionalidade e a ergonomia.

Seus processos de criação não seguem a linearidade esquemática das metodologias projetuais ensinadas nos cursos de graduação em design de moda; as quais, em geral, baseiam-se em pensar num tema, criar um painel de inspirações, conceber uma cartela de cores e então definir tecidos, formas, volumes etc. Nos procedimentos de Yamamoto, essas fases se misturam, ocorrem simultaneamente de modo que uma ideia pode ter diversos pontos de partida, configurando-se como um desenvolvimento bastante complexo.

Yamamoto entende o design de moda como um vetor social e cultural e se preocupa com o resgate de técnicas tradicionais. É possível perceber esse uso na sua coleção Histórias Rendadas (inverno/16), na qual utiliza a renda renascença, tradicional da região do Cariri pernambucano. Esta coleção é considerada pela designer como um de seus trabalhos mais importantes por conta do resgate de uma técnica tradicional de "uma região esquecida do país" (YAMAMOTO, 2017).

Outro dos principais pilares de suas criações é a valorização das pessoas que fazem as roupas. Na coleção que usa a renda renascença, Fernanda desenvolveu um 
documentário no qual aborda as histórias de vida das rendeiras, passando pelo aprendizado deste ofício e aspectos de seu cotidiano. Já na coleção Comunidade Yuba, Yamamoto realizou uma série de vídeos, nos quais cada integrante da equipe de design relata seu processo criativo. Para ela, é importante que as pessoas saibam que as roupas não saem prontas das máquinas, mas envolvem um intenso trabalho de pesquisa e de desenvolvimento técnico. A experimentação é um princípio muito presente nos seus projetos de coleção, como forma de incorporar imprevistos, os quais não necessariamente configuram-se como erros ou acertos, mas como parte de um caminho repleto de aprendizados.

\section{A COLEÇÃO DE ROUPAS REFERENCIADA PELA COMUNIDADE YUBA}

\subsection{A Comunidade Yuba: um breve contexto}

A Comunidade Yuba é formada por imigrantes japoneses e seus descendentes. Atualmente, segundo seu website ${ }^{4}$, é formada por quatro diferentes gerações de imigrantes e descendentes de japoneses, presentes em 24 famílias, que somam aproximadamente sessenta pessoas. 
Figura 1 - Localização do município de Mirandópolis, no interior do estado de São Paulo:

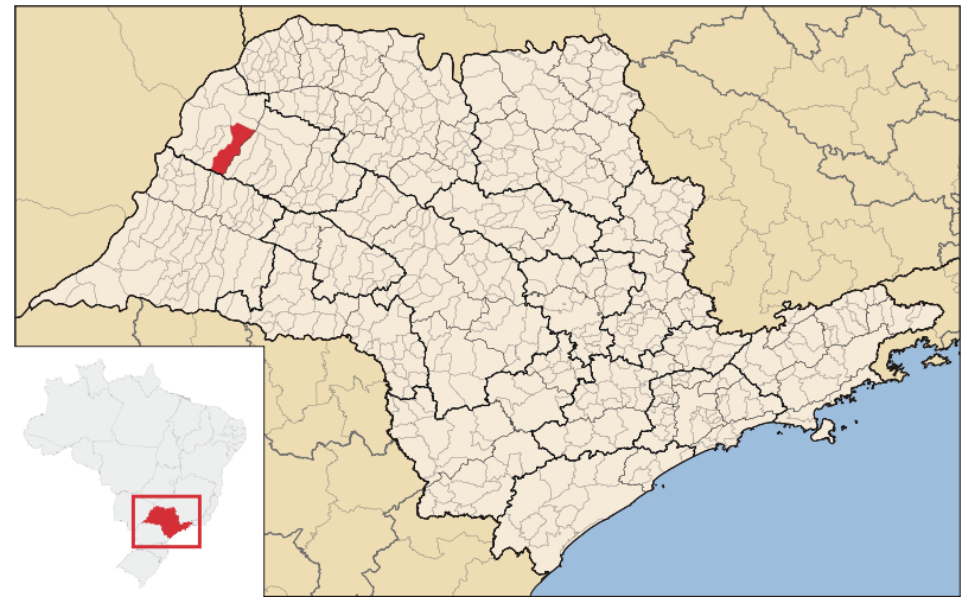

Fonte: https://pt.wikipedia.org/wiki/Mirand\%C3\%B3polis

Localizada no município de Mirandópolis, no interior paulista, foi idealizada e criada pelo imigrante japonês Isamu Yuba, em 1935. É "uma experiência rural camponesa [...] alicerçada no trabalho comunitário, na ajuda mútua e no autogovernabilidade" (MENDES, ALMEIDA, 2007, p. 113) e sustenta-se no tripé: "cultivar a terra, amar as artes e orar" (BARTABURU apud KANZAWA, 2010, p.12).

O objetivo de sua criação foi influenciado pelas leituras que Isamu Yuba teve do livro "Emílio", do filósofo suíço JeanJacques Rousseau, no qual encontra a ideia de que "a liberdade não está em nenhuma forma de governo, está no coração do homem livre" (BARTABURU apud KANZAWA, 2010, p. 10), o que o inspira a criar uma experiência comunitária auto-gestionária, não-hierárquica, em que o trabalho seja entendido como uma fonte de cultivo pessoal e prazer. Além disso, a Comunidade Yuba carrega consigo o valor de preservação da cultura japonesa através de diferentes elementos culturais, tais como a língua utilizada como a oficial da comunidade, as celebrações tradicionais, a culinária, dentre outros aspectos cotidianos. 
A família Yuba chega ao Brasil por volta de 1926, a partir do incentivo da Rikkokai, uma associação cristã, liderada pelo pastor Shigeshi Nagata e que desejava:

Ajudar jovens japoneses a recomeçar a vida do outro lado do mundo. [...]. Imaginou assentamentos que chamou de 'Alianças', onde os colonos teriam seu próprio quinhão de Novo Mundo para traçar o futuro do jeito que bem entendessem. Desde que, é claro, pudessem pagar pelas terras (BARTABURU apud KANZAWA, 2010, p. 10).

A valorização da vida enquanto um cultivo é muito importante para o modo de vida anticapitalista yubense de modo que não há circulação de dinheiro dentro de seus limites. Os trabalhadores não recebem salários por aquilo que realizam porque o objetivo do trabalho está mais alinhado a um "cultivo pessoal" e ao um "cultivo da própria comunidade" do que a benefícios financeiros. Sua atividade principal é a fruticultura e são grandes produtores de goiaba e quiabo, e a renda advinda destes trabalhos é de todos.

Em todas as noites, os yubenses se envolvem em atividades artísticas, pois o seu criador entendia que estas práticas tornam a vida mais inventiva e inovadora, fazendo com que o cultivo da sensibilidade interfira no desenvolvimento e qualidade da produção agrícola. Os yubenses desenvolvem aulas de balé, teatro, canto coral, recital com instrumentos, desenho, cerâmica e haicai .

\subsection{0 processo de criação da coleção Comunidade Yuba: documentos e relatos}

Este tópico foi desenvolvido a partir das entrevistas realizadas com a equipe de criação da marca Fernanda Yamamoto no mês de março de 2019. Conversamos com as 
designers Fernanda Yamamoto e Luciana Bortowski sobre os processos de desenvolvimento da coleção Comunidade Yuba.

O primeiro contato de Fernanda com Yuba se dá por conta do vínculo da designer com uma ex-moradora da comunidade, chamada Silvia Sassaoka. Assim, surge o convite para uma visita à comunidade no mês de julho de 2016. Junto ao seu companheiro, a designer vai até Yuba com a intenção de viver uma experiência pessoal e não necessariamente para desenvolver um trabalho. Assim, entende que as experiências na comunidade seriam uma temática fértil para seu trabalho, pois percebe "inspirações literais, estéticas [...]. Temas que façam sentido como uma experiência de vida [...] quando alguma coisa te toca, faz sentido para virar uma coleção" (YAMAMOTO, 2019, informação oral).

Luciana relata que as primeiras visitas da equipe à Yuba funcionaram como uma experiência do espaço. Eles se inseriram na rotina e buscaram viver as atividades diárias na comunidade, como lavar e secar louças, trabalhar na lavoura, frequentar as aulas de dança, participar de encontros, dentre outras vivências. Ao contrário do que um processo de criação em design costuma estabelecer, a busca de referências visuais mais claras neste projeto não foi um ponto de partida. A ideia que os guiava era o estilo de vida de Yuba e os modos como essa vivência poderia ser pensada como linguagem e técnicas para o design e confecção de roupas.

Para o ponto de partida da coleção, foram levadas em consideração especialmente duas características: a simplicidade e o fato de a comunidade fazer a maioria das coisas que consome. Parte-se de uma base simples e agregase diferentes elementos visuais, como cor, textura e volume. Inicialmente foram utilizadas cinco peças de tecidos brancos, sendo duas peças de linho, duas de algodão e uma de neoprene, que é uma referência do universo da marca. Como 
a Comunidade Yuba é autossustentável e produz um mínimo de resíduos sólidos, Fernanda traz isso a partir do recurso de zero waste. Os retalhos de tecidos são reutilizados para criar novas peças, até mesmo como base para as tramas de tricô, como podemos ver na figura 2.

Figura 2 - Tricô desenvolvido a partir de retalhos de tecidos:

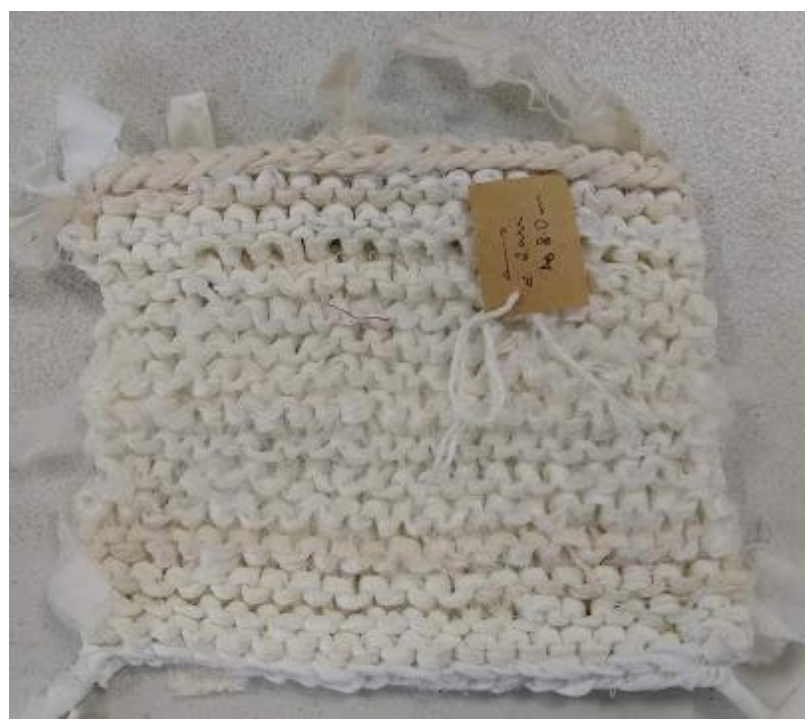

Fonte: Acervo das autoras

O plantio e o cultivo são primordiais na atividade agrícola de Yuba, e referenciam elementos desta coleção, como uma metáfora do próprio processo de mais de dois anos nos quais a equipe cria relações na experiência junto à Comunidade Yuba. Assim, o desenvolvimento desta coleção pode ser considerado como uma analogia em relação ao colher, ao alimentar e a aproveitar cada uma das partes da planta a ser gerada.

A técnica dos tingimentos naturais entra na coleção como forma de incorporar as plantas e o trabalho com a terra nas roupas. Assim, a equipe colheu algumas plantas em Yuba e, a partir de uma referência na cartela de cores desejada, experimentaram diferentes possibilidades. As 
experimentações de tingimento natural foram desenvolvidas com ajuda das tintureiras parceiras Marina Stuginsky e Claudia Fugita, especialmente para algumas cores específicas. As outras foram obtidas a partir de testes que funcionaram como uma outra forma de experimentar o tempo no desenvolvimento de uma coleção de design de moda: cada minuto, cada hora é capaz de mudar a tonalidade de uma cor. Por entenderem este processo como experimental, incorporaram as cores que saíram diferentes do objetivo inicial. Na figura 3, podemos ver alguns dos testes iniciais da cartela de cores para a coleção.

Figura 3 - Testes iniciais de cartela de cores desenvolvida a partir de tingimentos naturais com plantas:

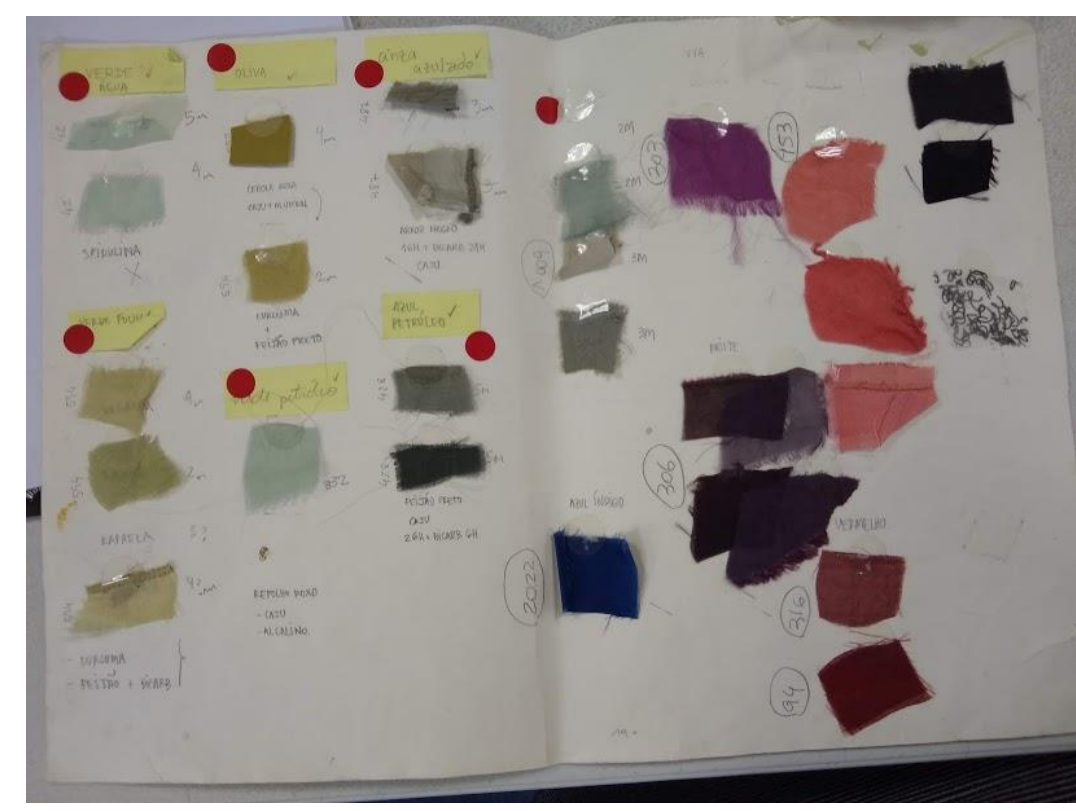

Fonte: Acervo das autoras

Com os tecidos já tingidos, outros elementos estéticos são agregados ao processo, tais como trabalhar com formas geométricas e pensar em formas de trazer texturas para os tecidos. Dois tipos de amarração de shibori são utilizados. Uma como costura que gera textura e outra que origina os 
plissados manuais, ao enrolar o tecido em um cano de PVC e marcá-lo com uma alta temperatura. Ambas são técnicas tradicionais japonesas reinventadas e são escolhidas como uma referência às tradições japonesas presentes em Yuba.

Outras formas de adquirir texturas foram o tricô, enquanto uma técnica manual e artesanal que está presente em algumas peças, como os aventais que são uma alusão à peça utilizada pelas cozinheiras de Yuba. As esculturas do artista e morador de Yuba já falecido, Hissao Ohara, tornaram-se referência para o formato das cerâmicas que compõem o bordado de algumas peças. Podemos ver os croquis de desenvolvimento destas peças na figura 4. Além das texturas, algumas peças foram desenvolvidas com estampas de retratos desenhados pela yubense Katsue para o seu livro "Bravos Pioneiros", que conta a história dos primeiros moradores de Yuba, vistos na figura de número 5.

Figura 4 - Croquis desenvolvimento dos aventais e inspirações no jardim de Yuba para as cerâmicas:

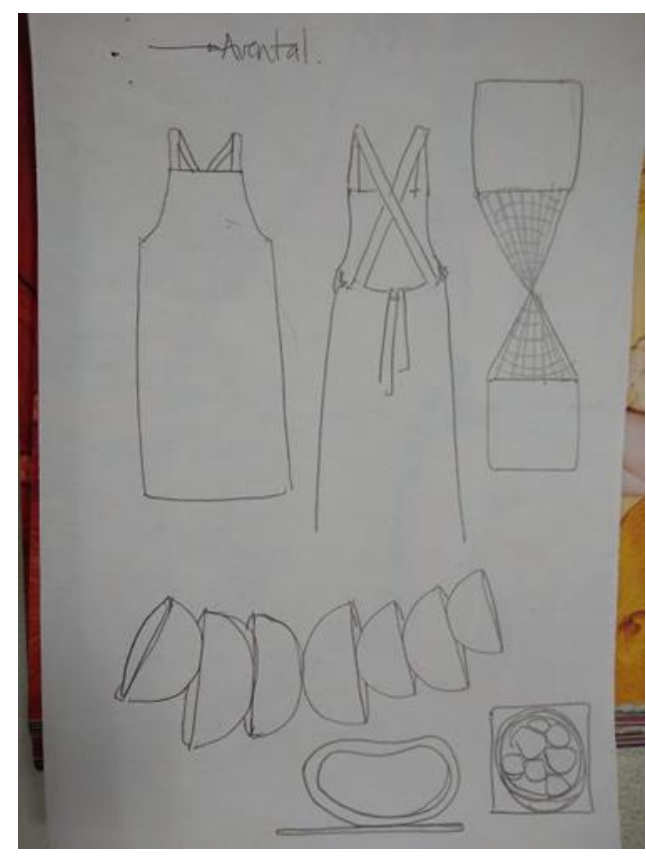

Fonte: Acervo das pesquisadoras 
Figura 5 - Retratos desenvolvidos por Katsue Yuba para o seu livro "Bravos Pioneiros

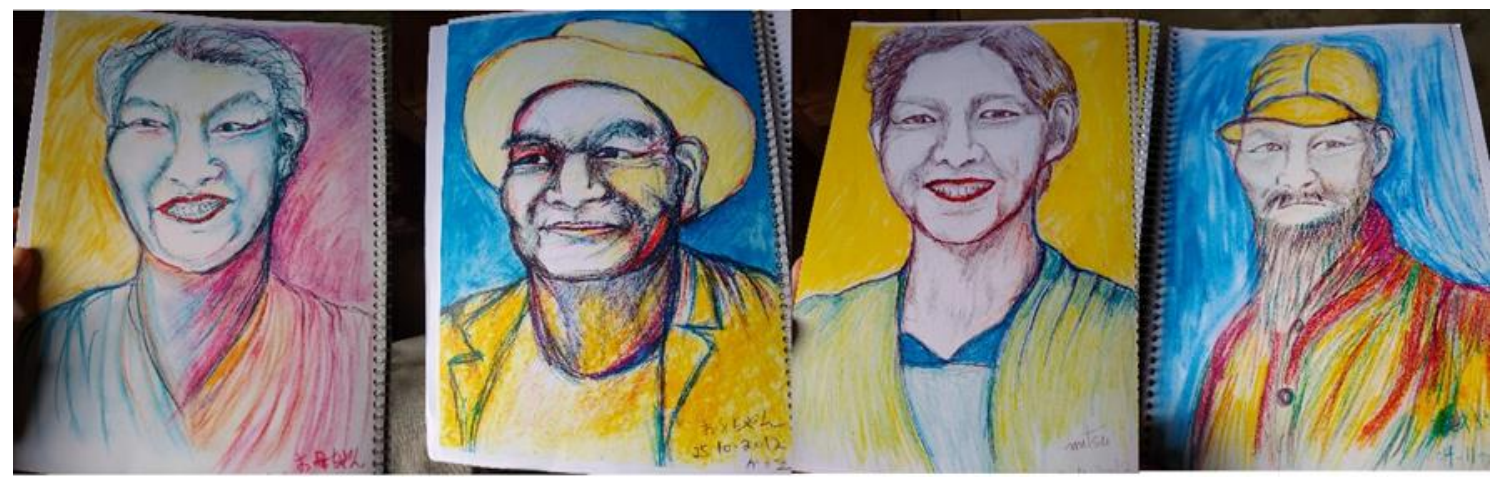

Fonte: Acervo das pesquisadoras

Como forma de retribuição e ressonância do funcionamento coletivo de Yuba, ao finalizarem o trabalho realizado junto à comunidade, a equipe tentou oferecer experiências para os moradores como uma forma de troca, por tudo que esta relação pôde produzir. Foi desenvolvida uma oficina de tingimento natural e shibori oferecida aos moradores da comunidade pela tintureira Claudia Fugita. Além disso, alguns moradores aprenderam a costurar algumas peças de roupa com o auxílio da equipe. Algumas peças de roupas das coleções inspiradas em Yuba foram entregues como presentes para algumas pessoas na comunidade.

\section{DA ESTÉTICA WABI-SABI: RELAÇÕES COM MODOS DE VIDA E ELEMENTOS VISUAIS}

No recorte deste trabalho, o enfoque está na estética wabisabi e em como ela emerge em diferentes elementos presentes da coleção e do desfile Comunidade Yuba. Cabe, neste contexto, a definição de estética japonesa ou de diferentes conceitos estéticos japoneses que passam a existir somente após o século XIX, no período de ocidentalização na 
Era Meiji , a partir da abertura do território japonês para os orientalistas europeus e da assimilação das ideias lógicas do pensamento ocidental (GREINER, 2017).

Neste contexto, estudar um conceito estético japonês não abarca uma tradução fiel e simplista, mas uma complexidade de um longo desenvolvimento histórico iniciado em tempos muito antigos e que, portanto, puderam originar uma multiplicidade de significados.

Neste sentido, entendemos que, antes de adentrarmos as estéticas wabi e sabi - ou wabi-sabi, precisamos passar pelas suas relações com o taoísmo e o zen budismo. Estas filosofias não se fazem presentes diretamente em nosso objeto de estudo, mas são mencionadas por incidirem justamente na relação entre estética e subjetivação, conexão que nos interessa neste trabalho.

Uma das concepções mais importantes da tradição budista que constitui o pensamento zen é uma aliança quase indissolúvel entre natureza e cultura. Há uma importância dada ao "fazer parte do fluxo", algo que marca a ligação entre corpo e natureza. Greiner nos lembra que "a natureza do si mesmo sempre foi processual e em fluxo, como a natureza" (GREINER, 2015, p. 27). A noção de fluxo pode ser entendida como mujō, ou impermanência (RICHIE, 2007), e está presente tanto no taoísmo como no pensamento zen: estar vivo no mundo é experenciar o fluxo e lidar com o presente. Não existe um eu cerrado, estamos sempre em processo, nunca finalizados, bem como não existe um estado permanente de um corpo, seja ele de dor ou de prazer. Portanto, a experiência da impermanência persiste na forma como experimentamos o tempo e a sua passagem. A experiência da temporalidade é inerente à experiência da vida, o que conecta humanidade e natureza. 
A influência destes pensamentos no desenvolvimento das artes no Japão faz com que elas valorizem menos o objetivo final e mais a vivência do caminho de aprendizado. É como se o trajeto vivido pudesse se assemelhar a uma prática de "cultivo pessoal". É o dō, entendido enquanto caminho, presente em diversas práticas artísticas japonesas como o aikidō, o kendō, o shodō, chadō, zendō, dentre outras. Neste contexto, "o que importa não é o fim e sim o meio, ou seja, a preparação do espírito, a concentração de praticar com 'a retidão dos sentidos' e 'firmeza de caráter'." (SATOMI, 2013, p. 42). O dō pressupõe, portanto, um aprendizado a partir da experiência. A importância do processo deriva da "concepção taoísta de que a imortalidade está na eterna mutação permeou todas as modalidades do seu pensamento" (OKAKURA, 2017, p. 49).

Assim, compreende-se que a estética wabi-sabi é a junção de duas estéticas que são conhecidas de modo separado nos estudos japoneses e aparecem de forma conjunta na grande maioria dos estudos ocidentais. Elas são muito difundidas no Japão, tendo sido até mesmo consideradas como a "essência da cultura nipônica" (SUZUKI apud OKANO, 2018, p. 184).

A arquiteta Michiko Okano (2018) realiza uma revisão bibliográfica bastante rica a respeito desta estética, passando pela etimologia das palavras e por diferentes perspectivas teóricas a respeito de ambas, abarcando estudos ocidentais e japoneses. A autora aponta os principais significados de wabi e sabi como sendo os seguintes:

Wabi, [...] proveniente do verbo wabiru: Sentirse solitário, miserável, desapontado, sem ânimo 1. Apreciar a vida reclusa e tranquila, longe das coisas mundanas 2 . Sentimento encontrado na refinada tranquilidade presente nas poesias haikai e na cerimônia do chá, sentimento melancólico e tranquilo na simplicidade 3. Pedir desculpas [..] Sabi [...] registra os seguintes significados: 4. Velho e elegante 5 . Sentimento 
de refinada tranquilidade 6 . Tipo de narração realizada a voz grave, forte, tremida 7 . Conceito básico existente na poesia haikai de Bashô (NIHON apud OKANO, 2018, p. 177 e 178)

O fato de estas palavras terem uma origem muito antiga, faz com que elas carreguem nos seus significados uma infinidade de transformações, em decorrência da passagem do tempo. É como se as palavras carregassem os seus percursos históricos, por terem percorrido um caminho e levassem esta mutabilidade consigo.

$\mathrm{Na}$ maior parte do acervo bibliográfico consultado, a origem da palavra wabi é relacionada à arte da cerimônia do chá. Porém, Okano aponta existirem registros anteriores em obras literárias da Era Nara (no século VIII) que o relacionam, por exemplo, ao sofrimento causado por um amor não correspondido. A partir de suas transformações históricas, wabi passa a estar relacionado com uma exaltação da vida simples, reclusa e rústica e, ainda, à grandeza presente na simplicidade. Neste caso, vale ressaltar que não se trata de uma apreciação a uma pobreza qualquer, mas de "um sentimento sofisticado e elegante, apesar de uma maneira de viver simples e rústica, longe de uma vida mundana, o que salienta a relação da estética com o modo de vida" (OKANO, 2018, p. 139).

Wabi relaciona-se à cerimônia do chá, pois o desenvolvimento do caminho do chá se sustenta na ideia de que a simplicidade da arquitetura de seu aposento e de sua decoração, pudesse transformá-la num "verdadeiro refúgio contra as vicissitudes do mundo externo." (OKAKURA, 2017, p. 82). E é desta maneira que, neste ambiente, pode brotar e pode-se cultivar a beleza das pequenezas da vida.

Os significados de wabi e a forma como o pensamento zen influencia o seu desenvolvimento histórico, nos conectam ao modo de vida yubense. Okano relata como esta estética está 
relacionada a pessoas que "abandonaram posições sociais, bens materiais e laços familiares e vivem isolados, em montanhas, em rústicas cabanas" (p. 140). Yuba congrega um modo de vida isolado dos desejos de consumo, tão presentes nos modos de subjetivação capitalísticos. Essa distância possibilita que lá se experimente a sensação de refúgio da produtividade capitalística, que permite o contato com as miudezas simples e bonitas da vida, tal como propõem os valores cultivados pela estética wabi. Deste modo, wabi configura-se como um cultivo pessoal por estar muito relacionado ao satori, o caminho da iluminação zen budista. Como coloca Okano, satori:

\begin{abstract}
Significa não estar atado aos valores impostos pela sociedade e buscar uma presença na ausência de coisas materiais, portanto não é a beleza de algo que é apenas simples e despretensioso, mas que deve também conservar a nobreza, a riqueza de espírito que, aparentemente e externamente, pode parecer rústica (OKANO, 2018, p. 141).
\end{abstract}

Sabi, por sua vez, é frequentemente relacionado à temporalidade. Por muitas vezes traduzido como "a pátina dos anos" (OKANO, 2018, p. 182), este elemento discorre sobre como o valor estético das coisas é realçado com o passar do tempo, valorizando a processualidade, o decorrer do tempo. Tem uma relação estreita com o pensamento zen e o taoísmo, pois, como apontamos, se relaciona com a impermanência que é inerente à experiência humana. Assim, sabi se relaciona com a ancestralidade e com a memória, pois traz consigo a ideia de que a beleza e o valor estético das coisas estão relacionados ao envelhecimento e ao tempo histórico.

Alguns dos estudos sobre estas estéticas realizados por autores ocidentais foram feitos por designers, como Andrew 
Juniper $(2011)^{5}$. Este designer define elementos visuais para apresentar estética wabi-sabi. Em um dos capítulos de seu estudo, Juniper realiza uma sistematização destes elementos, que de forma geral, estão relacionados com a natureza. A escolha de materiais naturais, como argila e cerâmica, tecidos provenientes de fibras naturais e métodos de tingimento naturais são citados pelo autor como características deste tipo de design. Também são mencionadas as composições opacas, sem brilho e monocromáticas. As formas e texturas de uma composição que parte do wabi-sabi emergem dos próprios materiais utilizados no processo criativo, portanto é comum que estejam presentes assimetrias.

Neste sentido, há uma relação entre o que é trazido por Juniper e a análise colocada por Okakura. Ele aponta que a sala em que é realizada a cerimônia do chá é "a morada assimétrica, por ser consagrada ao culto do imperfeito, que intencionalmente deixa algo inacabado para a imaginação completar" (OKAKURA, 2017, p. 68). Deste modo, a espacialidade presente no wabi-sabi seria entendida como um espaço vazio que relacionamos neste estudo ao ma ou espaço-entre, delineado como um espaço intervalar, prenhe de possibilidade e potência de criação. Está presente em toda a cultura japonesa, sendo mais do que um simples elemento estético, mas quase um senso comum cultural (OKANO, 2012). No próximo tópico, focaremos as conexões entre as roupas e a apresentação da coleção Comunidade Yuba e as referidas estéticas. 


\section{WABI-SABI NA COLEÇÃO COMUNIDADE YUBA}

Nosso olhar para o wabi-sabi presente no trabalho de Yamamoto, parte da ideia de que tanto wabi quanto sabi são elementos estéticos que carregam longos processos históricos e, no contexto abordado aqui, as relações com tradições culturais presentes nos processos de criação são ação e movimento. Como coloca Salles (2016):

A cultura não é um depósito de informações, é um mecanismo organizado, de modo extremamente complexo, que conserva as informações, elaborando continuamente os procedimentos mais vantajosos e compatíveis. Recebe as coisas novas, codifica e decodifica mensagens, traduzindo-as para um outro sistema de signos (SALLES, 2016, p. 69).

O desfile por Fernanda Yamamoto, é criado a partir da referência em um modo de vida anticapitalista de uma comunidade de descendentes de japoneses que preservam a sua cultura e ancestralidade, na qual o dinheiro não faz parte dos desejos ou do cotidiano. A história dos ancestrais comuns se torna importante como uma forma de conexão entre os seus membros. Ao colocar-se para viver temporariamente desta maneira, a equipe de criação de Fernanda Yamamoto transforma esta experiência em mais do que os elementos visuais ou as roupas criadas para um desfile, mas em um processo criativo que vive uma temporalidade mais vagarosa, que entende a importância do tempo para a criação e que, além disso, dimensão da simplicidade coloca como ponto de partida.

Utilizando como ferramenta de leitura os estudos de Juniper (2011), wabi-sabi aparece nas escolhas de materiais para o desenvolvimento das roupas. Como o modo de vida de Yuba está baseado na agricultura e na vida no campo, foram 
escolhidos materiais que fossem relacionados à natureza, tecidos provenientes de fibras naturais, como o algodão e o linho. Todas as cores das peças são processos de tingimento com plantas, como o urucum, o feijão preto, a spirulina e o cosmos - esta última colhida na própria comunidade. Em algumas outras peças, como o vestido da figura 6, estão presentes bordados feitos a partir de cerâmica, material que tem sua origem na argila.

Figura 6 - Presença de bordados feitos com cerâmicas

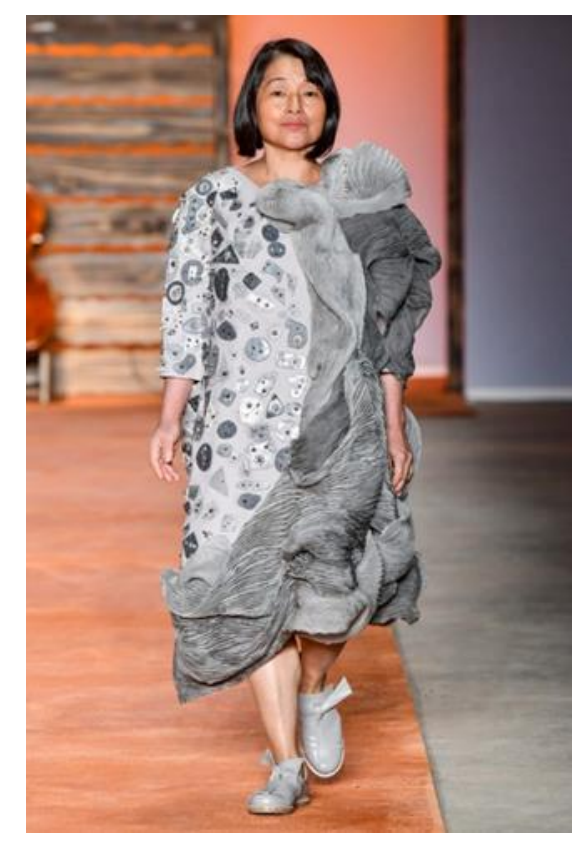

Fonte: http://www.fernandayamamoto.com.br/comunidadeyuba/

$\mathrm{Na}$ figura 7, podemos ver as cores da coleção. Como apontamos no tópico anterior, wabi-sabi é frequentemente relacionado a composições monocromáticas e a grande maioria das peças da coleção segue esta abordagem. Aquelas que não seguem este caminho, estão amparadas na ideia de sustentabilidade e do zero waste. Outros coloridos, por sua vez, se relacionam com wabi-sabi a partir do material. 
Figura 7 - Presença de cores na coleção

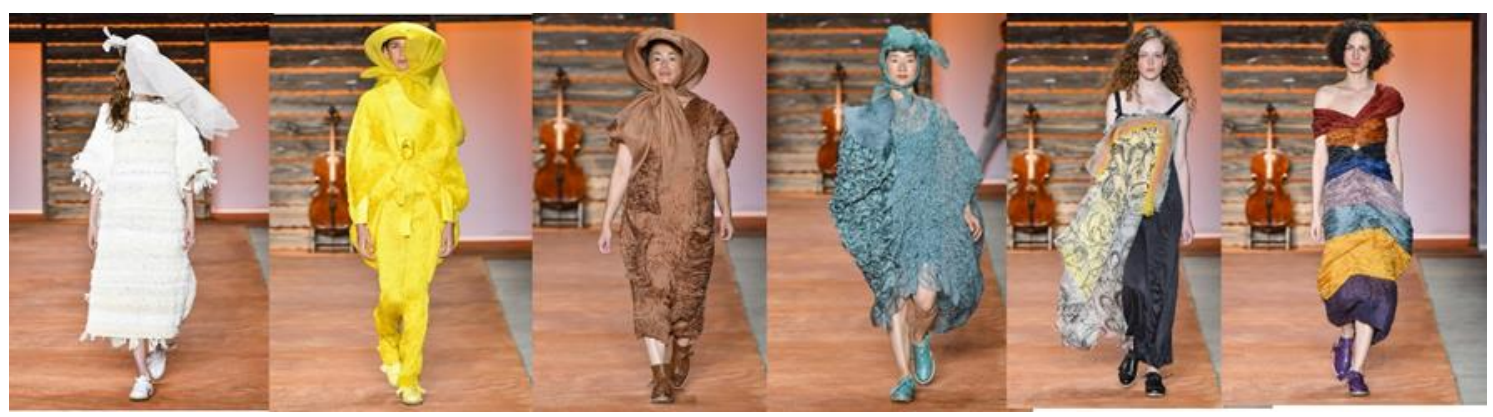

Fonte: http://www.fernandayamamoto.com.br

As formas das peças originam-se em retângulos, triângulos e círculos, que constroem as bases das peças desenvolvidas de modo simétrico e assimétrico. Esta escolha referencia-se na simplicidade da geometria plana e de suas possibilidades. Neste sentido, temos também a presença de rastros da estética japonesa conhecida como o "mínimo essencial", que consiste em tentar dizer o máximo pelo mínimo. Além disso, por serem inspiradas no jardim das esculturas da Comunidade Yuba, as formas geométricas também referenciam os bordados em cerâmica.

Para a produção de texturas, utilizam-se duas técnicas tradicionais japonesas de tingimentos. Em algumas peças, a costura utilizada na técnica de tingimento do shibori é utilizada como textura. Na técnica original, tinge-se o tecido com estas costuras para que se criem estampas nos tecidos. Porém, neste caso, elas foram utilizadas apenas pela sua forma. Uma outra técnica de amarração de shibori é utilizada como forma de criar plissados manuais, bastante inspirados em criações do designer japonês Issey Miyake ${ }^{6}$ Para esta técnica, amarra-se um tecido a um cano de PVC com um barbante que molda os plissados e fixa-se esta textura a partir 
do uso de altas temperaturas. Podemos ver o resultado destes trabalhos na figura 8 .

Figura 8 - Amarrações de shibori usadas como texturas e plissados

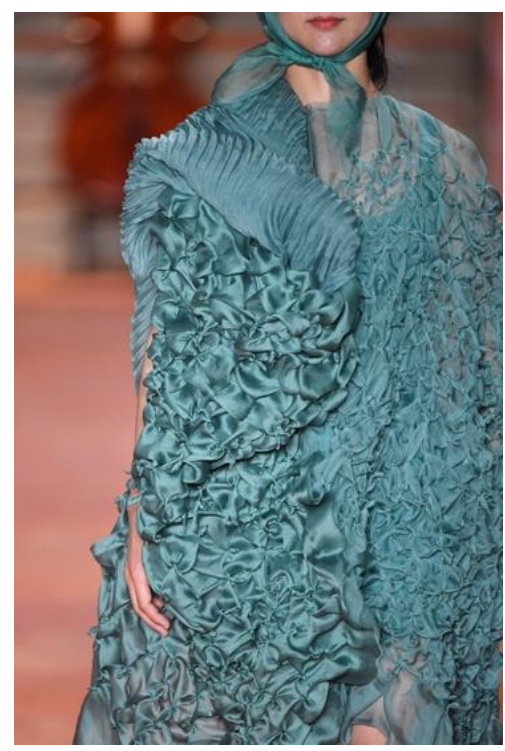

Fonte: http://www.fernandayamamoto.com.br/comunidadeyuba/

Juniper coloca a ideia de sobriedade como algo importante para a estética wabi sabi, enfocando a questão mais filosófica de um processo de criação. É importante ressaltar que alguns dos motivos que levam Yamamoto a incorporar elementos na coleção são pautados por aquilo que a afetou intimamente. Em uma abordagem de design voltada para a simplicidade que gera expressões por meio de um mínimo de elementos, as roupas, os vídeos e os catálogos a partir de histórias muito íntimas e pessoais que perpassam a vivência yubense e a experiência da própria equipe de Fernanda em Yuba. Esta intimidade é abordada em algumas peças, como o vestido desfilado pela yubense Renata Katsue, que leva as estampas feitas por ela mesma, na figura 9. 
Figura 9 - Katsue Yuba desfila roupa com estampas desenvolvidas a partir de seus desenhos

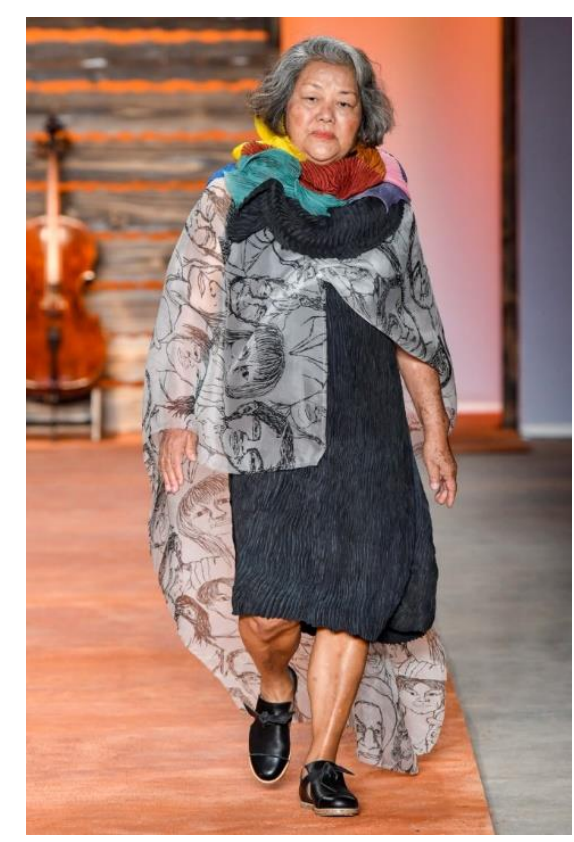

Fonte: http://www.fernandayamamoto.com.br/comunidadeyuba/

\section{CONSIDERAÇÕES FINAIS}

Nesta cartografia, pudemos olhar para estética wabi-sabi enquanto um rastro estético japonês presente na coleção Comunidade Yuba. Como foi exposto, está relacionada aos modos de vida e aos processos de subjetivação, não consistindo somente em elementos visuais ou materialidades, mas em uma presença sensível para uma experiência espaçotemporal.

Disparada pela vivência temporária da equipe de Fernanda Yamamoto junto à Comunidade Yuba, wabi-sabi se faz presente neste trabalho desde a fonte inspiradora, uma comunidade reclusa, de vida agrícola, muito próxima à natureza, da qual emergem os materiais naturais conectados à ideia de cultivo. Desta forma, podemos retomar a estética wabi na forma como Yuba se aproxima da ideia budista do satori, a iluminação distante dos valores capitalistas e com 
uma grande valorização da vida simples. Além disso, a estética sabi se relaciona com a valorização da ancestralidade, uma vez que dialoga com a passagem do tempo, com o envelhecer enquanto algo que torna as coisas mais belas. Neste trabalho, ela se materializa também em referências intencionais às tradições japonesas, presentes nas amarrações de shibori e na cerâmica.

Entendemos, portanto, que wabi-sabi emerge da experiência que Fernanda Yamamoto e sua equipe tiveram junto à Comunidade Yuba. Deste modo, uma estética que brota das reverberações semeadas pela experiência, o que aproxima a estética de um processo vital.

Este processo de criação, portanto, situa-se em uma rede composta pela cultura japonesa trazida pelos imigrantes japoneses no começo do século XX; os modos de subjetivação presentes em uma comunidade que busca a valorização de uma vida simples. Carrega, também, a leitura e a vivência que Fernanda Yamamoto e sua equipe trazem da experiência junto a esta comunidade, transformando-a em um produto de design, carregado de afetividade e traduzindo-os em elementos visuais, têxteis e artísticos.

Deste modo, podemos entender que wabi-sabi aparece em vestígios da coleção de Fernanda Yamamoto, por ser uma tradução daquilo que pode ser vivido em uma experiência comunitária na qual estas estéticas estavam presentes enquanto modo de vida, reverberando, então, nos elementos de design presentes na coleção.

\section{Notas}

1 Abordamos a ancestralidade a partir de estudos multidisciplinares, perpassando a filosofia e a psicanálise, que a entendem como a transmissão de memória cultural transgeracional 
que se dá a partir do tripé: ritos, mitos e o corpo. Para mais sobre o assunto, consultar Oliveira (2012) e Safra (2002);

2 A São Paulo Fashion Week é o maior evento de moda do Brasil e a quinta maior semana de moda do mundo. É realizado semestralmente e abriga a criação de importantes marcas e designers de moda brasileiros. A edição 45 aconteceu em abril do ano de 2018.

3 A clínica ampliada entendida aqui a partir da cartilha da Política Nacional de Humanização e que qualifica um modo de produção de saúde proposto para os serviços de saúde em conexão com usuários e comunidade. A escuta toma um lugar de importância nestas práticas, como forma de estar atento aos afetos que permeiam um tratamento de saúde, bem como entender o percurso que leva a um processo de adoecimento. Mais informações sobre a clínica ampliada em:http://bvsms.saude.gov.br/bvs/dicas/201_clinica_ampliada.ht $\mathrm{ml}$

4 Informações disponíveis em: http://www.fernandayamamoto.com.br (Acesso em 16/05/2019).

5 Entrevista concedida para o canal de Youtube "Um Olhar Entrevistas", disponível em : https://www.youtube.com/watch?v=zYYEgHdtN4k (Acesso em 15/9/2019)

$6 \mathrm{Um}$ projeto de design de moda passa por diferentes etapas que envolvem o planejamento da coleção que leva em conta definição de materiais, orçamento, público-alvo e gestão do tempo. A partir das etapas iniciais, desenvolve-se um painel - o moodboard - no qual se coletam as intenções da coleção, a partir de recortes, ideias de cores, aviamentos, tecidos e materiais que devem fazer parte da coleção. São criados os croquis que levam à modelagem para desenvolvimento de protótipos e, por fim, ao desenvolvimento da grade de peças.(JONES, 2005)

7 Entrevista concedida para o canal de Youtube Leonardo Pirondi, disponível em: https://www.youtube.com/watch?v=3zsIGyh66xM (acesso em 15/9/2019)

8 http://brasil-ya.com/yuba/historia/rekishi_por.html (acesso em 15/9/2019) 
9 Haicai ou haiku é uma forma de poesia japonesa curta e bastante imagética, na qual divide-se o poema em três versos de frases com 5, 7 e 5 palavras, respectivamente.

10 Entrevista realizada com a pesquisadora responsável pelo desenvolvimento desta pesquisa.

11 Zero waste é o nome dado para o tipo de produção em design de moda que visa produzir o mínimo possível de resíduos sólidos e têxteis em seu desenvolvimento.

12 Durante a Era Meiji (1868-1912), existe um incentivo para um processo de modernização do Japão, entendido, também, como um processo de ocidentalização das tecnologias presentes no país. Anteriormente, no período Tokugawa, em 1854, foi encerrada a política de isolamento japonês que perdurou por mais de duzentos anos.

130 taoísmo é uma tradição filosófica e religiosa originária do leste asiático. Seu nome deriva de "tao", a ideia de caminho que pode ser entendido como o entendimento intuitivo da vida, entendido a partir da experiência. (TAOÍSMO, 2019)

$14 \mathrm{O}$ zen budismo é uma corrente de budismo que se desenvolve na China, no século VII, a partir de influências do budismo indiano Mahayama e do taoísmo. A sua base prática é a meditação sentada, o zazen. (ZEN, 2019)

15 É possível tecer diversas críticas a uma leitura tão lógica de uma questão filosófica e estética que se aproxima tanto da vida. Porém, por ser um estudo realizado por um designer, entendemos que pode orientar o olhar para o nosso objeto de estudo de forma mais objetiva.

160 designer de moda japonês Issey Miyake possui uma linha de roupas chamada "Pleats Please" caracterizada pelo uso de plissados. 


\section{REFERÊNCIAS}

GREINER, Christine. Leituras do Corpo no Japão. São Paulo: N-1 edições, 2015. edições, 2017.

.Fabulações do Corpo Japonês. São Paulo: N-1 GUATTARI, Félix; DELEUZE, Gilles. Mil platôs - vol. 1. Editora 34, 2000.

JONES, Sue Jenkyn. Fashion design. Laurence King Publishing, 2005.

JUNIPER, Andrew. Wabi sabi: The Japanese art of impermanence. Tuttle Publishing, 2011.

MENDES, Eduardo Roberto; DE ALMEIDA, Rosemeire Aparecida. Algumas considerações sobre o geógrafo anarquista Piotr Kropotkin e a comunidade rural Yuba em Mirandópolis. (SP). REVISTA NERA, n. 11, p. 109-121, 2012.

OKAKURA, Kakuzo. O livro do chá. Editora Pensamento, 2017.

OKANO, Michiko. Ma: entre-espaço da arte e comunicação no Japão. São Paulo: Annablume, 2012.

A estética wabi-sabi: complexidade e

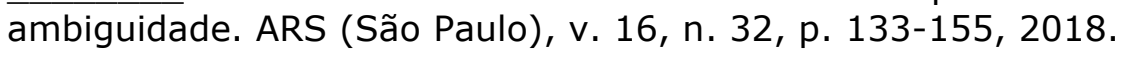

RICHIE, Donald. A tractate on Japanese aesthetics. Stone Bridge Press, 2007.

SALLES, Cecilia. Redes da criação-a construção da obra de arte. Horizonte, 2016.

SATOMI, AL Música japonesa transterritorial: atitude ética ou estética? In: SHIODA, Cecília Kimie Jo et al. Dô-caminho da arte: do belo do Japão ao Brasil. 2013. 